Disclosure of Interests: None declared

DOI: 10.1136/annrheumdis-2021-eular.550

\section{POS1337 BEHÇET'S DISEASE AND COURSE OF PREGNANCY - RESULTS FROM THE NATIONWIDE PREGNANCY REGISTER REVNATUS}

H. S. Koksvik ${ }^{1}$, B. Jakobsen ${ }^{1}$, H. Bjørngaard ${ }^{1}$, C. Skorpen ${ }^{2,3}$, M. Wallenius ${ }^{1,2}$. ${ }^{1}$ St. Olavs Hospital, Trondheim University Hospital, Norwegian National Advisory Unit on Pregnancy and Rheumatic Diseases, Trondheim, Norway; ${ }^{2}$ NTNU, Department of Neuromedicine and Movement Science, Trondheim, Norway; ${ }^{3}$ Alesund Hospital, Department of Rheumatology, Alesund, Norway

Background: Behçets disease (BD) is a complex and multisystemic disorder of unknown etiology. It is characterized by recurrent oral and genital ulcers and inflammatory eye involvement. It can also affect the cardiovascular, pulmonary and skeletal system. BD is commonly diagnosed in women in reproductive age. Pregnancy outcomes are reported in previous studies with discrepancies in the rate of pregnancy-related complications.

Objectives: To describe the course of pregnancy in patients with BD

Methods: We prospectively collected data on pregnancy outcome in women with $\mathrm{BD}$ through the nationwide Norwegian registry on pregnancy and rheumatic diseases (RevNatus) from 2016-2020. All women were diagnosed with ICD-10 code M35.2. 13 pregnancies in 11 women were recorded. One women had two pregnancies including one twin birth.

Results: Median age at conception was 30 years (range 25-32), with median disease duration 7 years (range 1-15). There were no serious organ manifestations. Tnf-alpha-inhibitors were used in $2^{\text {nd }}$ trimester in 3 pregnancies. All pregnancies resulted in live births with median gestational age at delivery of 38 weeks (range 36-41). No preeclampsia or HELLP were recorded.

\section{Table 1. Pregnancy outcome in 13 BD pregnancies}

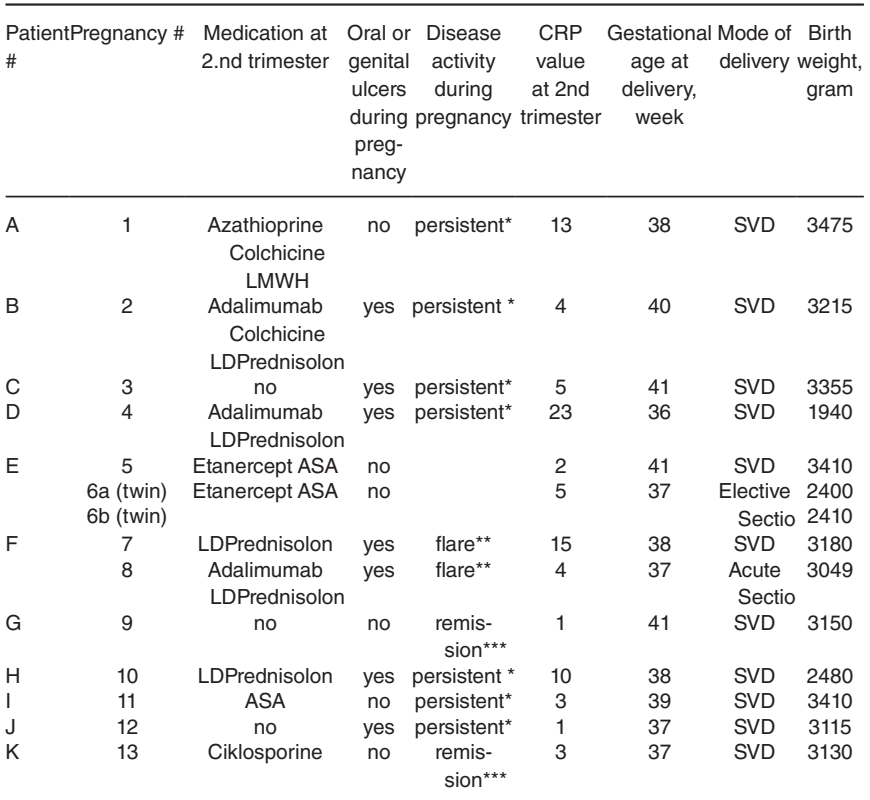

SVD = spontaneous vaginal delivery, ASA = acetylsalicylic acid, LDPrednisolon = Low dose Prednisolon $<10 \mathrm{mg} /$ day, ${ }^{*}=$ persistent throughout pregnancy, ${ }^{* *}=$ flare once during pregnancy, ${ }^{* * *}=$ remission throughout pregnancy

Conclusion: Pregnancies in women with BD in this cohort were uncomplicated. We did not reveal any serious events, and they all resulted in live births. However, $\mathrm{BD}$ is a very heterogeneous disease, and the women in our cohort did not have any serious organ manifestations. Larger cohorts representing the heterogeneity are needed to study the course and outcome of pregnancies in BD.

Disclosure of Interests: None declared

DOI: 10.1136/annrheumdis-2021-eular.666

\section{POS1338 INCIDENCE, PREVALENCE, AND MORTALITY OF CHRONIC PERIAORTITIS: A POPULATION-BASED STUDY}

U. Ghaffar $^{1}$, K. J. Warrington ${ }^{1}$, S. Duong ${ }^{2}$, C. S. Crowson ${ }^{1,2}$, M. Burke ${ }^{1}$, B. Viers ${ }^{3}$, A. Potretzke ${ }^{3}$, H. Bjarnason ${ }^{4}$, M. Koster ${ }^{1} .{ }^{1}$ Mayo Clinic College of Medicine and Science, Rheumatology, Rochester, United States of America;

${ }^{2}$ Mayo Clinic School of Health Sciences, Biomedical Statistics and Informatics,
Rochester, United States of America; ${ }^{3}$ Mayo Clinic College of Medicine and Science, Urology, Rochester, United States of America; ${ }^{4}$ Mayo Clinic College of Medicine and Science, Vascular and Interventional Radiology, Rochester, United States of America

Background: Chronic periaortitis is an inflammatory condition that typically involves the infrarenal portion of the abdominal aorta. Few studies are available to outline the epidemiology of this rare condition. To date, no epidemiologic stud ies on periaoritis have been performed in North America.

Objectives: To evaluate the epidemiology, presentation and outcomes of patients with chronic periaortitis from 1998 through 2018.

Methods: An inception cohort of patients with incident chronic periaortitis from January 1, 1998 through December 31, 2018, in Olmsted County, Minnesota USA, was identified based on comprehensive individual medical record review utilizing the Rochester Epidemiology Project medical record linkage system. Inclusion required radiographic and/or histologic confirmation of periarterial soft tissue thickening around at least part of the infra-renal abdominal aorta or the common iliac arteries. Data were collected on demographic characteristics, clinical presentation, renal and radiographic outcomes, and mortality. Incidence rates were age and sex adjusted to the 2010 United States white population.

Results: Eleven incident cases of chronic periaortitis were identified during the study period. Mean \pm SD age at diagnosis was $61.8 \pm 13.4$ years. The cohort included 9 men (82\%) and 2 women (18\%). The most common presenting symptom was pain with $55 \%(6 / 11)$ reporting abdominopelvic-pelvic pain, $36 \%(4 / 11)$ back pain, and 18\% (2/11) flank pain. Obstructive uropathy was present in $73 \%$ (8/11) subjects: $3(27 \%)$ unilateral left, 1 (9\%) unilateral right, and $4(36 \%)$ bilateral. Mean creatinine at presentation was $2.7 \pm 3.4 \mathrm{mg} / \mathrm{dL}$. Ureteral stenting was required at diagnosis in seven patients: unilateral left in 2, unilateral right in 1 and bilateral in 4. All 11 patients received glucocorticoids with a median (IQR) dose of $40(30,60) \mathrm{mg} /$ day. Additional non-glucocorticoid therapeutics were used in 10 patients.

Renal function stage at last follow up declined in 2 patients, remained the same in 3 patients and improved in 6 patients. Mean creatinine at last follow-up was $1.2 \pm 0.2 \mathrm{mg} / \mathrm{dL}$. Among the seven patients requiring baseline indwelling ureteral stent placement only two required ongoing ureteral stenting at last follow up. None of the four patients without ureteral stenting at diagnosis progressed to require stenting during the follow-up period. No patient underwent ureterolysis surgery in this cohort. Periarterial soft tissue thickening at last follow up had increased in thickness in $1(9 \%)$, was unchanged in $2(18 \%)$, decreased in size but did not resolve in 6 (55\%), and fully resolved in $18 \%$.

Age- and sex-adjusted incidence rates per 100,000 population were 0.26 for females, 1.56 for males and 0.87 overall. Overall prevalence on January 1, 2015 was 8.98 per 100,000 population. Median (IQR) length of follow-up was 10.1 (2.5 13.8) years. Overall mortality was similar to the expected age, sex, and calendar estimates of the Minnesota population with standardized mortality ratio $(95 \% \mathrm{Cl})$ for the entire cohort $2.07(0.67,4.84)$

Conclusion: This study reports the first epidemiologic data on chronic periaortitis in the United States. In this cohort of patients with chronic periaortitis, men were approximately 4 times more commonly affected than women. Mortality was not increased compared to the general population.

Disclosure of Interests: None declared

DOI: 10.1136/annrheumdis-2021-eular.698

\section{POS1339 \\ MORE FREQUENT AND EARLIER HIP INVOLVEMENT IN SPONDYLOARTHRITIS ASSOCIATED WITH FAMILIAL MEDITERRANEAN FEVER}

M. Bektaș ${ }^{1}$, S. Sarı ${ }^{1}$, C. Cetin ${ }^{1}$, B. Ç. Yalçın Dulundu ${ }^{1}$, N. Koca ${ }^{1}$, B. Ince ${ }^{1}$, Y. Yalçınkaya ${ }^{1}$, B. Artim-Esen ${ }^{1}$, M. Inanc ${ }^{1}$, M. L. Ocal ${ }^{1}$, A. Gül ${ }^{1}{ }^{1}$ Istanbul Faculty of Medicine, Internal Medicine, Rheumatology Division, Istanbul, Turkey

Background: Familial Mediterranean fever (FMF) is a hereditary autoinflammatory disorder caused by the MEFV gene variants. Although association between FMF and spondyloarthritis (SpA) has previously been reported, clinical and laboratory features of patients with FMF and SpA have not been defined in detail.

Objectives: We aimed to evaluate clinical and laboratory characteristics, disease outcome and biologic responses of patients with FMF+SpA compared to patients with only SpA who were followed-up in our tertiary referral center.

Methods: Database of FMF Clinic was screened for FMF patients with coexistent $\mathrm{SpA}$ and 113 patients were identified fulfilling Tel Hashomer and ASAS criteria for FMF and SpA, respectively. A group of patients with SpA without FMF matched for age, gender and disease duration were selected as the control group.

Results: Thirteen patients were excluded because of missing data, and 100 patients (F/M: 52/48) were included into the analysis. Mean follow-up time was $93.6 \pm 77$ (range[r]: 3-324) months and mean patient age was $43.3 \pm 12$ ( $\mathrm{r}: 20-87)$ years. Mean age of onset for FMF was $12.5 \pm 8$ ( $r$ : 1-36) and for SpA was $25 \pm 11$ ( $r: 7-72$ ) years. SpA findings was classified as axial in $35.4 \%$, axial and peripheral in $47.9 \%$ and only peripheral in $16.7 \%$ in FMF+SpA group. Half (49\%) of the 
patients had hip involvement (70\% bilaterally), and $21.5 \%$ of them needed total hip joint replacement (TJR), which were significantly more frequent compared to control group. Two exon 10 MEFV variants were found in $69.4 \%$, and most $(69.8 \%)$ had homozygous M694V. Hip involvement was more frequent in patients with two exon 10 variants $(p=0.036$; $O R=4.4)$ compared to those with one variant; and TJR was more frequent in those with homozygous M694V compared to other exon 10 variants $(p=0.001 ; O R=10)$. Radiographic sacroiliitis was less frequent in patients with homozygous M694V ( $p=0.019$; OR=5.48). HLA-B27 positivity was not associated with hip or axial involvement in patients with FMF+SpA.

Biologics were used in 60 patients (anti-TNF in 43, secukinumab in 1, and tocilizumab in 2). Anti-IL-1 drugs were used in 23 patients for refractory FMF. In 9 patients, anti-TNF and anti-IL-1 drugs were tried for refractory joint involvement: 5 switched to anti-TNFs from anti-IL-1, 4 patients switched to anti-IL-1 from antiTNFs. Biologic DMARD requirement was more frequent in patients with two exon 10 variants $(p=0.006$; $O R=7.4)$, especially in those with homozygous M694V $(p=0.006$; OR=7.6). Although anti-IL-1 usage did not differ among MEFV variants, anti-TNF was used more frequently in patients with homozygous M694V $(p=0.007 ; O R=7.2) . F M F+S p A$ patients had higher serum CRP and developed amyloidosis more frequently than those patients with $\mathrm{SpA}$.

Table 1. Comparison of clinical and laboratory findings between the patients with FMF+SpA and SpA control

\begin{tabular}{lccc}
\hline & FMF + SpA $(\mathrm{n}=100)$ & $\mathrm{SpA}(\mathrm{n}=217)$ & P value \\
\hline Age (years) & & & \\
Sex (n, \%) & $43.3 \pm 12$ & $43.4 \pm 11$ & 0.6 \\
Male & 48 & $104(47.9)$ & 0.99 \\
Female & 52 & $113(52.1)$ & \\
Duration of SpA (monnths)* & $181.6 \pm 108$ & $180.2 \pm 112$ & 0.8 \\
Age onset of SpA (years)* & $25.1 \pm 11$ & $28.4 \pm 8$ & 0.008 \\
Peripheral arthritis (n, \%) & $35 / 80(43.8)$ & $79 / 212(37.3)$ & 0.3 \\
HLA-B27 positivity (n, \%) & $6 / 21(28.6)$ & $105 / 139(75.5)$ & $<0.001(\mathrm{OR}=18.9)$ \\
CRP (mg/dL) & $26.7 \pm 25^{\star *}$ & $18.96 \pm 29$ & 0.001 \\
ESR (mm/hour) & $39.7 \pm 27$ & $39.4 \pm 28$ & 0.8 \\
Hip involvement (n, \%) & $47 / 96(49)$ & $23 / 118(19.5)$ & $<0.001(\mathrm{OR}=20.9)$ \\
TJR (n, \%) & $20 / 93(21.5)$ & $8 / 205(3.9)$ & $<0.001(\mathrm{OR}=23.3)$ \\
Fulfilling mNY criteria (n, \%) & $52 / 81(64.2)$ & $164 / 199(82.4)$ & $0.001(\mathrm{OR}=10.8)$ \\
Biologic DMARD (n, \%) & 60 & $68 / 214(31.8)$ & $<0.001(\mathrm{OR}=22.5)$ \\
Anti-TNF $(\mathrm{n}, \%)$ & 46 & $68 / 214(31.8)$ & $0.015(\mathrm{OR}=5.96)$ \\
Amyloidosis (n, \%) & 16 & $5 / 205(2.4)$ & $<0.001(\mathrm{OR}=19.3)$ \\
\hline
\end{tabular}

${ }^{*}$ mean \pm standard deviation, ${ }^{*}$ during the attack-free period

Conclusion: In this group of FMF+SpA patients, hip involvement and need for TJR were more frequent and associated with penetrant MEFV variants rather than HLA-B27 positivity. These patients had higher inflammatory response and risk of developing amyloidosis, and they needed biologics more frequently compared to SpA group. More severe disease course in $\mathrm{FMF}+\mathrm{SpA}$ patients requires further attention and analysis in larger cohorts.

Disclosure of Interests: None declared

DOI: 10.1136/annrheumdis-2021-eular.716

\section{POS1340 MULTICENTER STUDY OF 71 PATIENTS WITH REFRACTORY UVEITIS RELATED TO IMMUNE- MEDIATED INFLAMMATORY DISEASES ON CERTOLIZUMAB PEGOL TREATMENT}

J. L. Martín-Varillas ${ }^{1}$, V. Calvo-Río ${ }^{2}$, L. Sanchez-Bilbao², I. González-Mazón², A. Adan ${ }^{3}$, I. Hernanz Rodríguez ${ }^{3}$, A. Gallego ${ }^{4}$, E. Beltrán ${ }^{5}$, S. Castro ${ }^{6}$, P. Fanlo ${ }^{7}$ A. García Martos ${ }^{8}$, I. Torre-Salaberri ${ }^{9}$, M. Cordero-Coma ${ }^{10}$, J. De Dios-Jiménez Aberásturi ${ }^{11}$, Á. García-Aparicio ${ }^{12}$, M. Hernández-Garfella ${ }^{13}$, A. SanchezAndrade $^{14}$, A. García-Valle ${ }^{15}$, O. Maiz ${ }^{16}$, R. Miguélez ${ }^{17}$, S. Rodríguez Montero ${ }^{18}$, A. Urruticoechea-Arana ${ }^{19}$, R. Veroz Gonzalez ${ }^{20}, A$. Conesa ${ }^{21}$, C. FernándezCarballido $^{22}$, V. Jovani ${ }^{23}$, O. Martínez González ${ }^{24}$, P. Moya ${ }^{25}$, S. RomeroYuste $^{26}$, P. Rubio Muñoz ${ }^{27}$, E. Peña Sainz-Pardo ${ }^{28}$, M. A. González-Gay ${ }^{2}$, J. L. Hernández ${ }^{2}$, R. Blanco ${ }^{2} .{ }^{1}$ Hospital Sierrallana, Rheumatology, Torrelavega, Spain; ${ }^{2} \mathrm{H}$. U. Marqués de Valdecilla, Rheumatology, Santander, Spain $;{ }^{3} \mathrm{H}$. Clinic, Ophthalmology, Barcelona, Spain; ${ }^{4}$ H.U. de Badajoz, Rheumatology, Badajoz, Spain; ${ }^{5} \mathrm{H}$. del Mar, Rheumatology, Barcelona, Spain; ${ }^{6} \mathrm{H}$. U. Joan XXIII, Rheumatology, Tarragona, Spain; ${ }^{7}$ C.H. de Navarra, Internal Medicine, Navarra, Spain; ${ }^{8} \mathrm{H}$. U. del Tajo, Rheumatology, Madrid, Spain; ${ }^{\circ} \mathrm{H}$. Basurto, Rheumatology, Bilbao, Spain; ${ }^{10}$ C.A.U. de León, Ophthalmology, León, Spain; ${ }^{11}$ H. U. de Álava, Rheumatology, Vitoria, Spain; ${ }^{12}$ C.H.U. de Toledo, Rheumatology, Toledo, Spain; ${ }^{13}$ H.G.U. de Valencia, Ophthalmology, Valencia, Spain; ${ }^{14}$ H. Lucus Augusti, Rheumatology, Lugo, Spain; ${ }^{15}$ C.A.U. de Palencia, Rheumatology, Palencia, Spain; ${ }^{16}$ H.U. Donostia, Rheumatology, San Sebastian, Spain; ${ }^{17}$ H. Móstoles, Rheumatology, Madrid, Spain; ${ }^{18}$ H.U. Virgen de Valme, Rheumatology, Sevilla, Spain: ${ }^{10} \mathrm{H}$. Can Misses, Rheumatology, Ibiza, Spain: ${ }^{20} \mathrm{H}$. Merida, Rheumatology, Mérida, Spain; ${ }^{21}$ H.G.U. de Castellón, Rheumatology, Castellón, Spain; ${ }^{22}$ H. San Juan, Rheumatology, Alicante, Spain; ${ }^{23}$ H.G.U. de Alicante, Rheumatology,
Alicante, Spain; ${ }^{24}$ H.C.U. de Salamanca, Rheumatology, Salamanca, Spain; ${ }^{25}$ H. Santa Creu i Sant Pau, Rheumatology, Barcelona, Spain; ${ }^{26}$ C.H.U. de Pontevedra, Rheumatology, Pontevedra, Spain; ${ }^{27} \mathrm{H}$. de l'Esperit Sant, Rheumatology, Barcelona, Spain; ${ }^{28}$ H.U. 12 de Octubre, Pediatrics, Madrid, Spain

Background: Prognosis of non-infectious refractory uveitis has improved markedly with biologic therapy (BT) (1-5). Most data are with monoclonal anti-TNF drugs, especially Adalimumab (ADA) and Infliximab (IFX). However, there is not enough evidence for the use of Certolizumab Pegol (CZP).

Objectives: To evaluate the efficacy and safety of CZP in refractory uveitis secondary to Immune-Mediated Inflammatory Diseases (IMID).

Methods: Multicenter study of 71 patients with uveitis due to IMID refractory to glucocorticoids and conventional immunosuppressants. Efficacy was assessed with the following ocular parameters: best corrected visual acuity (BCVA), anterior chamber cells, vitritis, macular thickness and presence of retinal vasculitis. These outcomes were compared between baseline, 1st week, 1st and 6th month, and 1st and 2nd year. Statistical analysis was performed with IBM SPSS Statistics v.23.

Results: 71 patients/100 affected eyes $(29 \mathrm{men} / 42$ women) with mean age of $40.0 \pm 11.3$ years were studied. Underlying IMIDs were: spondyloarthritis $(n=38)$, Behçet (10), psoriatic arthritis (8), Crohn disease (3), sarcoidosis (2), JIA (1), reactive arthritis (1), rheumatoid arthritis (1), relapsing polychondritis (1), TINU (1), pars planitis (1), Birdshot (1) and idiopathic uveitis (3). Uveitis pattern was anterior $(n=55)$, posterior (6), panuveitis (6) and intermediate (4).

Prior to CZP, patients had received: methotrexate (37), sulfasalazine (26), azathioprine (14), cyclosporine (10), leflunomide (3), mycophenolate mofetil (3) and cyclophosphamide (1). Previous BT was administered in 48 (67.6\%) patients, with a mean of $1.4 \pm 1.3$ drugs per patient as follows: ADA ( $n=56)$, IFX (27), golimumab (14), tocilizumab (5) and etanercept (3). Pregnancy was the reason for prescribing CZP in 19 patients. CZP was administered in monotherapy $(n=39)$ or combined with conventional immunosuppressants $(n=32)$.

After a mean follow-up of $27.1 \pm 21.1$ months, most of the ocular variables showed a rapid and significantly improvement (Table 1 ). A decrease in the median number [IQR] of flares of uveitis before and after CZP, $(3[1-4]$ vs. 0 [0-1], $p<0.001)$ was observed. CZP was discontinued in 15 patients due to remission $(n=2)$, ocular insufficient response (2) and incomplete response of extraocular manifestations (11). No serious adverse events were reported.

Conclusion: CZP seems to be effective and safe in patients with refractory uveitis due to IMID.

REFERENCES:

[1] Martín-Varillas JL, et al. Ophthalmology 2018; 125:1444-1451. doi: 10.1016/j. ophtha.2018.02.020.

[2] Atienza-Mateo B, et al. Arthritis Rheumatol 2019; 71:2081-2089. doi: 10.1002/ art.41026.

[3] Santos-Gómez M, et al. Clin Exp Rheumatol 2016; 34(6 Suppl 102):S34S40. PMID: 27054359

[4] Vegas-Revenga N, et al. Am J Ophthalmol 2019; 200:85-94. doi: 10.1016/j. ajo.2018.12.019

[5] Calvo-Río V, et al. Clin Exp Rheumatol. 2014; 32 (4 Suppl 84):S54-7. PMID: 25005576

Table 1.

\begin{tabular}{|c|c|c|c|c|c|c|}
\hline & Baseline & $1^{\text {st }}$ week & $1^{\text {st }}$ Month & $6^{\text {th }}$ Month & $1^{\text {st }}$ year & $2^{\text {nd }}$ year \\
\hline BCVA $($ mean \pm SD) & $0.68 \pm 0.27$ & $0.72 \pm 0.27^{*}$ & * $0.79 \pm 0.25^{*}$ & $0.84 \pm 0.24^{*}$ & $0.85 \pm 0.25^{*}$ & $0.87 \pm 0.22^{*}$ \\
\hline $\begin{array}{l}\text { Improvement } \\
\text { in AC Cells, } \\
\mathrm{n}(\%) \text { Patients } \\
\text { with AC cells at } \\
\text { baseline }(n=48)\end{array}$ & - & $21(43.7)$ & $30(62.5)^{\star}$ & $41(85.4)^{\star}$ & $48(100)^{\star}$ & $48(100)^{\star}$ \\
\hline $\begin{array}{l}\text { Improvement in } \\
\text { Vitritis, } \mathrm{n}(\%)\end{array}$ & - & $3(23.1)$ & $8(61.5)^{*}$ & $11(84.6)^{\star}$ & $13(100)^{*}$ & $13(100)^{\star}$ \\
\hline \multicolumn{7}{|l|}{$\begin{array}{l}\text { Patients with vitri- } \\
\text { tis at baseline } \\
\quad(n=13)\end{array}$} \\
\hline $\begin{array}{l}\text { OCT }(\mu) \\
\quad(\text { mean } \pm \text { SD })\end{array}$ & $292.5 \pm 47.7$ & $294 \pm 47.4$ & $286.7 \pm 41.9^{\star}$ & $274.7 \pm 38.7^{\star}$ & $272.8 \pm 38.9^{\star}$ & $266.31 \pm 36.2^{*}$ \\
\hline $\begin{array}{l}\text { Choroiditis; } \\
\text { affected eyes, } \\
n,(\%)\end{array}$ & $3(4.2)$ & $3(4.2)$ & $2(2.8)$ & $2(2.8)$ & $1(1.4)$ & $0(0)$ \\
\hline $\begin{array}{l}\text { Retinal Vasculitis; } \\
\text { affected eyes, } \\
\mathrm{n},(\%)\end{array}$ & $2(2.8)$ & $0(0)$ & $1(1.4)$ & $0(0)$ & $0(0)$ & $0(0)$ \\
\hline
\end{tabular}

Disclosure of Interests: None declared

DOI: 10.1136/annrheumdis-2021-eular.1233 